\title{
Modeling Developmental Language Difficulties From School Entry Into Adulthood: Literacy, Mental Health, and Employment Outcomes
}

\begin{abstract}
James Law Robert Rush

Centre for Integrated Healthcare Research, Queen Margaret University, Edinburgh, United Kingdom

Ingrid Schoon Institute of Education, University of London, United Kingdom

Samantha Parsons

Centre for Longitudinal Studies, Institute of Education, University of London, United Kingdom
\end{abstract}

Purpose: Understanding the long-term outcomes of developmental language difficulties is key to knowing what significance to attach to them. To date, most prognostic studies have tended to be clinical rather than population-based, which necessarily affects the interpretation. This study sought to address this issue using data from a U.K. birth cohort of 17,196 children, following them from school entry to adulthood, examining literacy, mental health, and employment at 34 years of age. The study compared groups with specific language impairment (SLI), nonspecific language impairment (N-SLI), and typically developing language (TL).

Method: Secondary data analysis of the imputed 5-year and 34-year data was carried using multivariate logistic regressions.

Results: The results show strong associations for demographic and biological risk for both impairment groups. The associations are consistent for the N-SLl group but rather more mixed for the SLI group.

Conclusions: The data indicate that both SLI and N-SLI represent significant risk factors for all the outcomes identified. There is a strong case for the identification of these children and the development of appropriate interventions. The results are discussed in terms of the measures used and the implications for practice.

KEY WORDS: specific language impairment, nonspecific language impairment, literacy, mental health, employment

$\mathrm{T}$ here has now been a series of well-documented clinical studies tracking developmental language difficulties across childhood (Johnson et al., 1999; Richman, Stevenson, \& Graham, 1982; Silva, Williams, \& McGee, 1987; Stothard, Snowling, Bishop, Chipchase, \& Kaplan, 1998; Tomblin et al., 1997) and into adulthood (Clegg, Hollis, Mawhood, \& Rutter, 2005; Felsenfeld, Broen, \& McGue, 1992, 1994). Of particular concern is the emerging body of literature that suggests that early communication difficulties, especially when reported in selected clinical populations, should be considered risk factors for a range of negative sequelae associated with low literacy levels (Im-Bolterm \& Cohen, 2007; Tomblin, 2005), poor mental health (Nelson, Benner, Stern, \& Stage, 2006; Snowling, Bishop, Stothard, \& Kaplan, 2006), and unemployment (Felsenfeld et al., 1994; Howlin, Mawhood, \& Rutter, 2000).

It has been established from population cohorts that early reading difficulties have long-term consequences for employment opportunities and psychological well-being (Bynner, Joshi, \& Tsatsas, 2000; Schoon et al., 2002). The implications of early language difficulties are less clear, 
especially when biological and social risk are taken into consideration (Reilly et al,. 2007; Tomblin, Hammer, \& Zhang, 1998; Zaichik, Tomblin, Smith, \& Xuyang, 1997; Zubrick, Taylor, Rice, \& Slegers, 2007).

Historically, a distinction has commonly been drawn between specific and more general language impairment. Specific language impairment (SLI) is defined by the identification of a discernible discrepancy between language and nonverbal performance while those with nonspecific language impairment (N-SLI) have comparable levels of difficulty in the two domains (Plante, 1998; Stark \& Tallal, 1981). The assumption is made that there is a substantive and meaningful difference between those who do and do not have specific difficulties. Although concerns have been raised about this approach (Cole, Dale, \& Mills, 1992; Thomas \& Karmiloff-Smith, 2002), discrepancy scores, or "cognitive referencing," are still commonly used to identify cases and allocate resources. Of particular concern is whether those with N-SLI and SLI are qualitatively different in terms of etiology and outcome. For example, although it is widely recognized that poor language skills are associated with demographic factors (Dollaghan et al., 1999; Hart \& Risley, 1995; Locke, Ginsborg, \& Peers, 2002), it is sometimes assumed that this is not the case for SLI (Conti-Ramsden \& Botting, 1999) or that there is something special about SLI that functions independently of social disadvantage (Fazio, Naremore, \& Connell, 1996).

One of the outstanding questions, and probably one of the best tests of the validity of the use of the term SLI, is what happens to children with SLI over time. Does their profile merge with other children with more pervasive difficulties, or does the "specific" nature of their difficulties protect them in some way from subsequent problems? It has recently been suggested that N-SLI and SLI may be discrete in terms of their heritability (HayiouThomas, Oliver, \& Plomin, 2005). Genetic influences were found to be modest in both groups relative to environmental influence, with a reduced group heritability for the SLI (.18) relative to the N-SLI group (.52). A significant extension of this is the role played by receptive language difficulties. Receptive and expressive language difficulties commonly co-occur (Bishop, 2006), yet it would appear to be the case that although there is high heritability for expressive skills (Monaco \& The SLI Consortium, 2007), the same does not appear to be the case for receptive language skills (Clark et al., 2007; Kovas et al., 2005). This, in turn, suggests there may be a higher environmental loading on receptive than expressive language difficulties. This might lead one to assume that children with specific receptive language difficulties might be more susceptible to both positive and negative environmental influences. In fact, the reverse appears to be the case, at least insofar as intervention for receptive language difficulties is concerned (Law, Garrett, \& Nye, 2004).
Key to this whole discussion is the epidemiological construct known as the "continuum of reproductive casualty" (discussed in Lubker \& Tomblin, 1998, p. 8), which represents the extent to which the level of a condition corresponds to the level of demographic and biological risk. Are the most severe cases of language difficulty also those most at biological and demographic risk? The only way to address such issues is to study the level of risk in large-scale, representative populations. Of course, much depends on the way that such risks are characterized, but it is clear that there is a need to integrate biological risk with risks associated with specific aspects of the child's environment, about which much has been learned over the past half century. It is also helpful to capture the difference between distal variables - those that are relatively immutable for that individual (whether the child's mother smoked during pregnancy, gender, etc.)—and proximal variables, which might be more readily amenable to change (whether the parent read to the child, overcrowding, etc.). The present study was set up to compare the link between demographic and biological risk factors in both SLI and N-SLI at 5 years of age, relative to children with typically developing language, and then examine the association between those early difficulties and environmental factors on three key adult outcomes, namely literacy, mental health, and employment status.

\section{Research Questions}

1. What is the extent of the relationship between proximal, distal, and biological factors and both SLI and $N$-SLI at school entry? Here, we hypothesize that although there will be an association with demographic factors and language learning difficulties at school entry, these associations will be less pronounced for the SLI group. It is also anticipated that proximal variables, those closest to the child, will have a greater impact than distal variables.

2. What is the risk associated with early developmental language difficulties in terms of literacy, mental health, and employment at 34 years? We hypothesize that children with both SLI and N-SLI at 5 years will present with discernible associations with literacy, mental health difficulties, and employment but that these associations will be stronger for the N-SLI than the SLI group. It is further anticipated that the associations between early language learning difficulties and adult outcomes will decrease considerably once demographic factors are taken into consideration.

\section{$\overline{\text { Methodology }}$ The Data Source}

The study draws on data collected for the 1970 British Cohort Study (BCS70), one of Britain's richest 
resources for the study of human development. ${ }^{1}$ The British Cohort Study takes as its participants 17,196 persons living in Great Britain who were born in 1 week in 1970. Data are available on cohort members at birth, $5,10,16,26$, and 30 years, and most recently in 2004 at 34 years. Demographic information was supplemented by a wide range of parental reports of their child's domestic experience, school reports, tests, and medical examinations. Children whose first language at home was not English and whose ethnicity was not White-European were excluded from the study because this group is likely to be at risk, at least in the early years, of lower language skills because of competing linguistic input. The data from this cohort have been described in a number of publications, the most comprehensive description of the 5 -year data set being Osborn, Butler, and Morris (1984).

Alongside the extensive parental reports of medical/ demographic history, child development, service usage, and the like, the BCS70 included two measures at 5 years of age that we have used in this study to identify our sample. The two measures were the English Picture Vocabulary Test (EPVT; Brimer \& Dunn, 1962) and the Copying Designs Test (CDT; Osborn et al., 1984). The EPVT is an adaptation of the American Peabody Picture Vocabulary Test (Dunn, 1965) and consists of 56 sets of four different pictures. The child is asked to point out the one picture that corresponds to the given word, and the test proceeds with words of increasing difficulty until he or she makes five mistakes in a run of eight items. In the CDT, the child is required to make two copies of eight designs (shown in the test booklet, which is reproduced in Osborn et al., 1984). The items were scored according to a series of specific characteristics (e.g., shape, symmetry, and angles) with total scores ranging from 0 to 8 . A zero score was obtained when the child attempted to copy at least one design but all attempts were judged to be poor. In terms of the subsequent analysis, the level of correlation between the language and drawing/copying measures was not especially high (.34), suggesting that these measures, although associated, do not overlap (Osborn et al., 1984).

Inevitably, there are limitations in the extent to which results from data collected more than 30 years ago can be extrapolated to the present day. The measures may have been restandardized, and there are likely to have been changes to the way in which professionals construe the concepts being tapped. That said, the measures are comparable to those used nowadays, although they would now only be a part of any test battery. Nevertheless, difficulties understanding vocabulary do underpin most of the more severe language difficulties, and copying tasks

\footnotetext{
${ }^{1}$ See www.esds.ac.uk/longitudinal/access/bcs70/133229.asp for all relevant information concerning this study.
}

of the type described here continue to be used as a part of nonverbal measures. Thus, the difficulties inherent in interpreting data from assessments in common usage many years ago have to be offset against the great methodological advantages offered by the size and longevity of cohorts like the BCS70.

In addition to the performance measures, a number of variables were identified at 5 and 34 years. These are separated into distal and proximal social risk factors (Schoon, 2006) and biological risk and developmental health. Distal risks represent factors perceived to be likely influences on child development over which there is no direct control. Those adopted in this study were gender, whether the child's mother left school before the age of 16 , and whether the mother was a single parent. Proximal risks are factors that might be considered modifiable in the sense that a parent might be encouraged to take literacy classes, to read more to their child, or to change a child's accommodation. Those adopted in this study were a measure of overcrowding in the home (the person per room ratio), whether the child had experienced preschool of any sort, whether either parent reported reading to the child, and whether the parent reported themselves to be a poor reader. We also included a number of biological and developmental health risks. Those adopted in this study were whether the mother had smoked during pregnancy, whether the child was born small for gestational age (calculated as a function of birth weight and gestation, namely with weight below $2,515 \mathrm{~g}$ and gestational age over 259 days), and whether the child had neurotic or antisocial behavioral difficulties as measured on the Rutter Behaviour Scale (Rutter, Tizard, \& Whitmore, 1970). Finally, we were aware that report of child performance on the measures identified did not necessarily correspond to whether parents and professionals thought there was any need for the children to receive help for their communication skills. It would obviously have been helpful to have the BCS70 data linked explicitly to clinical and other data sources at the time. These were not available, and by way of a proxy for this type of concern we included parental report of whether the child had been seen by a speech-language therapist. Although this clearly is not a risk in itself, it can be regarded as an indication of clinical concern.

The 34-year independent measures included an adult literacy assessment split at Level-2 literacy (with poor literacy being defined as equivalent to a grade $\mathrm{D}$ or lower in the national General Certificate of Secondary Education [GCSE] exam). Adult mental health at age 34 was assessed from the following four measures:

A shortened version comprising nine items of the Rutter Malaise Inventory (Dex \& Joshi, 2004). The shortened scale has acceptable internal consistency $(\alpha=.76)$. Correlations between the shortened and full version of the 
scale calculated from responses to the questions in the age 26 and age 30 surveys of BCS70 were both .90 . A score of 4 or higher is used to indicate psychological distress $(9.9 \%)$.

A measure of general satisfaction with life. Participants were asked, "On a scale from 0 to 10, how satisfied are you about the way your life has turned out so far?" $(0=$ extremely unsatisfied, $10=$ completely satisfied $)$. The median score was $7 ; 22.1 \%$ of respondents scored between 0 and 6 .

A measure of how much feeling of control over life the individual has. The forced-choice two-option question read, "I usually have a free choice and control over my life" or "Whatever I do has no real effect on what happens to me" (4.6\%).

A measure of self-efficacy from another forced-choice two-option question: "I usually get what I want out of life" or "I never really seem to get what I want out of life" (11.0\%).

The four indicators of adult mental health had acceptable internal consistency $(\alpha=.71)$. Adults with poor mental health at age 34 were identified as those for whom three or four indicators suggest lowered levels of adult mental well-being. This applied to $7.2 \%$ of our sample (7.04\% of men, $7.4 \%$ of women). Comparatively, $68.3 \%$ (69.2\% of men, $67.4 \%$ of women) had no sign of poor mental well-being as measured by these four indicators. Employment was defined in terms of the time, in months, that respondents had spent unemployed between April 1986 and March 2004.

\section{Operationalizing the Language Groups at 5 Years}

The children were separated into three discrete groups based on their performance on the EPVT and CDT. The first, designated the typical language (TL) group, had both EPVT and CDT scores falling within normal limits - that is, not more than $1 S D$ below the mean score on both scales. The TL group was then compared with two groups of children with developmental language difficulties. The first of these was designated the nonspecific language impairment group (N-SLI) and had EPVT scores two or less standard deviations below the mean and CDT scores below normal limits-that is, $1 S D$ or more below the mean score. The second group was designated the specific language impairment group (SLI) and also had scores of two or less standard deviations below the mean on the EPVT but had scores of greater than $1 S D$ below the mean on the CDT (i.e., within normal limits). Both the $2 S D$ cut-off and the $1 S D$ discrepancy were selected to reflect the criteria in the ICD-10 (F80.2; World Health Organization, 1993). All children falling within the SLI group would have a discrepancy of at least $1 S D$ between their verbal and nonverbal performance, the level of difference recommended in the identification of SLI (Stark \& Tallal, 1981). This strict application of discrepancy scoring would specifically exclude children who might be accepted as having SLI in clinical practice with much fewer pronounced discrepancies between verbal and nonverbal performance.

It is important to emphasize that children with SLI would conventionally be identified using a range of different measures, often focusing on grammar and morphology as much as receptive vocabulary. Our aim here was to establish a level of difficulty that would be most likely to predict poor outcomes but not to capture the profile of the full range of children who might be identified with speech and expressive language difficulties using contemporary diagnostic criteria. To avoid any potential confusion it might be more accurate to describe the target group as children with specific receptive vocabulary difficulties, but we have retained the use of the terms SLI and N-SLI because they are commonly recognized and because, without further assessment information when the children were 5 years of age, we would not be able to specify the level of their expressive language or speech difficulties.

\section{Participants}

A total of 11,330 children were assessed on the EPVT and the CDT at 5 years. Of these, 1,259 children had scores between $-1 S D$ and $-2 S D$ on the EPVT and were excluded from the analysis, leaving 10,071 children eligible for inclusion in the study. Of the remaining children, 8,726 (86.6\%) fell into the TL group, 195 (1.9\%) fell into the N-SLI group, and 211 (2.1\%) fell into the SLI group. There were a further $939(9.3 \%)$ who fell into a fourth group, those with good language scores and poor performance on the copying test, who were also not considered further in this analysis. The process of the identification of the target groups from the overall sample is described in Figure 1.

\section{$\overline{\text { Analysis }}$}

A series of multiple logistic regressions was undertaken to assess the independent effect (odds ratio and 95\% confidence interval) of the factors within the distal, proximal, and biological risk and developmental health blocks, with SLI and then N-SLI compared to TL at 5 years. In each case, a model combining all the factors was reported for each group (SLI/N-SLI). A similar approach was adopted for the adult outcomes, that is, literacy at 34 years (below Level 2/Level 2), mental 
Figure 1. Flow diagram indicating the derivation of the sample. BCS70 $=1970$ British Cohort Study; EPVT $=$ English Picture Vocabulary Test; CDT = Copying Designs Test.

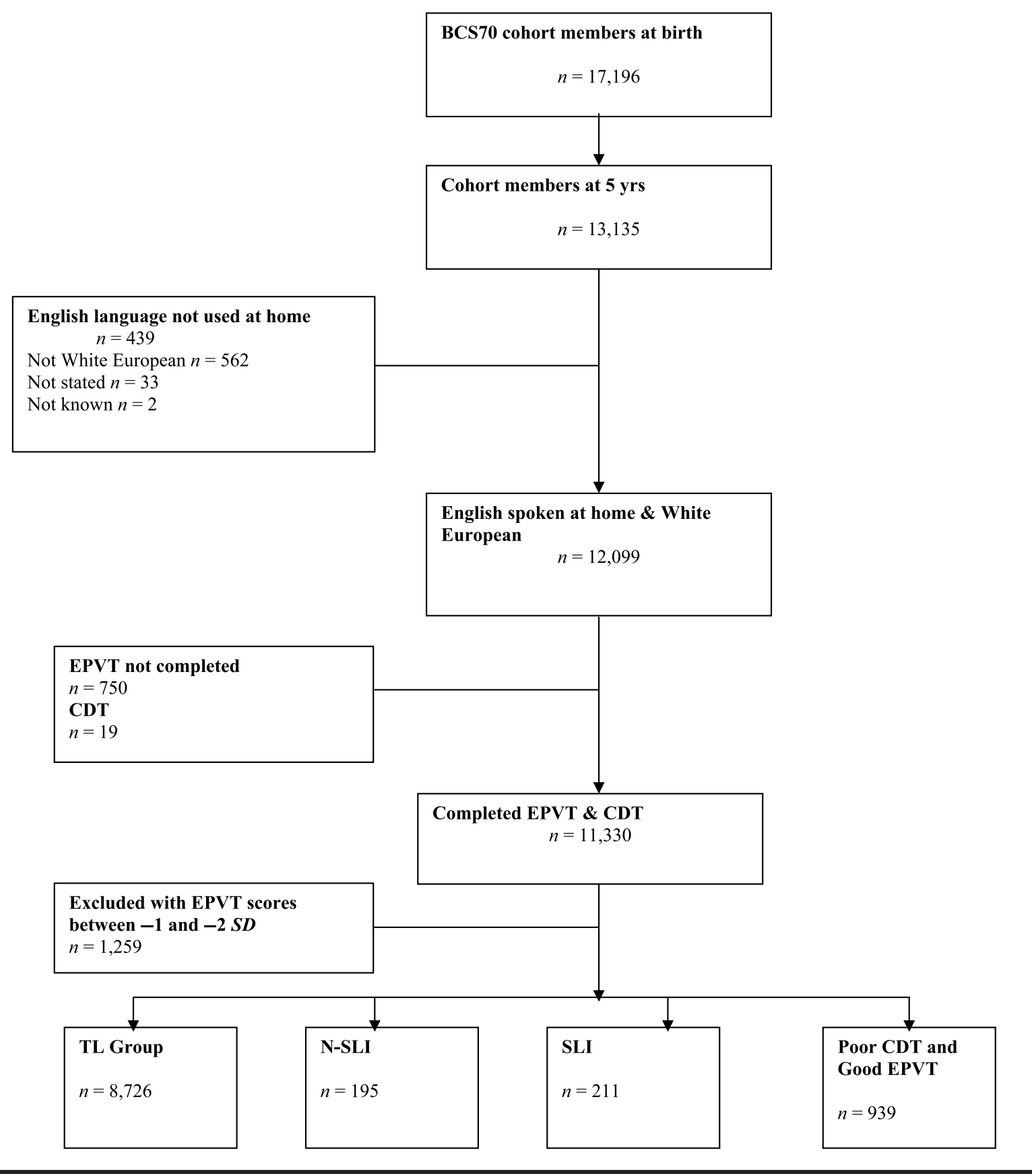

health at 34 years (no signs/3-4 signs), and time spent in unemployment (1 year or less/more than 1 year). These analyses were carried out with SPSS version 13.0 for Windows, and the significance level adopted throughout was .05, two-sided.

To optimize the data, any information that was missing for the 11,330 BCS70 cohort members in our sample who completed the EPVT and CDT at age 5 was imputed for the age 34 outcomes. The method of imputation employed was multiple imputation by chained equations (MICE), implemented in STATA 10 (Royston, 2004). The dataset contained all variables used in the logistic regression analyses and other background variables known to be related to poor early language and adult literacy performance. Five replicates of the data were created. Model estimates were averaged across these five analyses, with their standard errors calculated according to Rubin's rule (Rubin, 1987). 


\section{$\overline{\text { Results }}$}

Table 1 compares sociodemographic characteristics and background data of all respondents, differentiating between those identified as being in the TL group, the N-SLI group, and the SLI group. Compared to children with normal language skills, those with SLI or N-SLI skills were more likely to have been small for gestational age, to have had a mother who smoked during pregnancy, and to have seen a speech and language therapist, and were more likely to be a girl. Children who were in the SLI or N-SLI group were slightly more likely than those with typical language skills to have behavioral difficulties. Far fewer mothers of cohort members with SLI or N-SLI had participated in extended education. Children manifesting poor language skills were more likely to be born to fathers working in unskilled or partly skilled manual jobs (Registrar General Social Classes IV or V; Rose, 1995) compared to children with competent language skills. Both SLI and N-SLI children were also slightly more likely to have lived with a single mother. Regarding their housing situation, cohort members with SLI or N-SLI were more likely to have spent their childhood in overcrowded accommodations. SLI and N-SLI children were less likely to have attended preschool and to have been read to, and their parents were more likely to be poorer readers themselves.

\section{Research Question 1: What is the extent of the relationship between proximal, distal, and biological factors and both SLI and N-SLI at school entry?}

Of the Distal factors, Table 2 shows that cohort members whose mothers left education at the minimum age were twice as likely to have SLI as those who had typical language ability. There was a small association for gender, with boys being less likely to have SLI than girls. Of the proximal factors, cohort members living in overcrowded housing or with no preschooling were roughly 1.5 times as likely to have SLI than those in the TL group at 5 years. Those cohort members whose parents were poor readers were nearly 3 times as likely to have SLI. In terms of biological risk and developmental health, a 50\%-70\% increase in the odds of having SLI was observed for

Table 1. Descriptives for children with typically developing language (TL), nonspecific language impairment (N-SLI), and specific language impairment (SLI) at 5 years of age.

\begin{tabular}{|c|c|c|c|c|}
\hline Descriptive & & TL $n(\%)$ & SLI $n(\%)$ & N-SLI $n(\%)$ \\
\hline \multicolumn{5}{|c|}{ Distal factors } \\
\hline \multirow[t]{2}{*}{ Gender } & Boy & $4,610(52.8)$ & $94(44.5)$ & $92(47.2)$ \\
\hline & Girl & $4,116(47.2)$ & $117(55.5)$ & $103(52.8)$ \\
\hline \multirow[t]{2}{*}{ Mother left school } & Post 15 & $3,124(37.0)$ & $48(23.1)$ & 20 (10.5) \\
\hline & Left by 15 & $5,308(63.04)$ & $160(76.9)$ & 170 (89.5) \\
\hline \multirow[t]{2}{*}{ Mother single parent } & All others & $8,210(97.1)$ & $201(96.6)$ & $171(90.0)$ \\
\hline & Single & $246(2.9)$ & $7(3.4)$ & $19(10.0)$ \\
\hline \multicolumn{5}{|c|}{ Proximal factors (age 5) } \\
\hline \multirow[t]{2}{*}{ Person per room ratio } & Less than 1 & $5,715(66.2)$ & $102(49.3)$ & $64(33.7)$ \\
\hline & $1+$ per room & $2,912(33.8)$ & $105(50.7)$ & $126(66.3)$ \\
\hline \multirow{2}{*}{ Child had some kind of preschool } & Yes & $6,617(77.3)$ & $129(62.9)$ & $88(48.4)$ \\
\hline & No & $1,944(22.7)$ & $76(37.1)$ & $94(51.6)$ \\
\hline \multirow[t]{2}{*}{ Parent read to child in past week } & Yes & 7,102 (83.3) & $145(71.4)$ & $109(57.4)$ \\
\hline & No & $1,428(16.7)$ & $58(28.6)$ & $80(42.6)$ \\
\hline \multirow{2}{*}{ Parent a poor reader } & No & $7,852(97.6)$ & $175(92.6)$ & $142(81.6)$ \\
\hline & Yes & $196(2.4)$ & $14(7.4)$ & $32(18.4)$ \\
\hline \multicolumn{5}{|c|}{ Biological risk and developmental health } \\
\hline \multirow{2}{*}{ Mother smoked during pregnancy } & No & $5,128(60.9)$ & $99(47.6)$ & $80(42.3)$ \\
\hline & Yes & $3,298(39.1)$ & $109(52.4)$ & $109(57.7)$ \\
\hline \multirow[t]{2}{*}{ Child small for gestational age } & No & $7,934(97.1)$ & $184(93.9)$ & $141(86.5)$ \\
\hline & Yes & $237(2.9)$ & $12(6.1)$ & $22(13.5)$ \\
\hline \multirow[t]{3}{*}{ Child with behavioral difficulties } & None & $7741(91.0)$ & $173(85.2)$ & $140(75.3)$ \\
\hline & Neurotic & $276(3.2)$ & $8(3.9)$ & $13(7.0)$ \\
\hline & Antisocial & $490(5.8)$ & $22(10.8)$ & $33(17.7)$ \\
\hline \multirow{2}{*}{ Child ever seen a speech-language therapist } & No & 7,855 (96.7) & $180(92.8)$ & $151(83.4)$ \\
\hline & Yes & $265(3.3)$ & $14(7.2)$ & $30(16.6)$ \\
\hline
\end{tabular}


Table 2. Multiple logistic regression predicting SLI at 5 years of age.

\begin{tabular}{|c|c|c|c|c|}
\hline Odds Ratio $95 \% \mathrm{Cl}$ & Model 1 & Model 2 & Model 3 & Final Model \\
\hline \multicolumn{5}{|c|}{ Distal factors } \\
\hline \multirow[t]{2}{*}{ Gender (Boy) } & $0.72^{*}$ & & & $0.60^{* *}$ \\
\hline & 0.550 .95 & & & $0.43-0.84$ \\
\hline \multirow[t]{2}{*}{ Child mother left school at minimum age } & $1.96^{* * *}$ & & & 1.33 \\
\hline & $1.41-2.71$ & & & $0.90-1.96$ \\
\hline \multirow[t]{2}{*}{ Mother a single parent } & 1.11 & & & 0.51 \\
\hline & $0.52-2.38$ & & & $0.12-2.09$ \\
\hline \multicolumn{5}{|c|}{ Proximal factors (age 5) } \\
\hline \multirow[t]{2}{*}{ Overcrowding } & & $1.66^{* *}$ & & $1.47^{*}$ \\
\hline & & $1.21-2.26$ & & $1.04-2.08$ \\
\hline \multirow[t]{2}{*}{ Child had no preschooling } & & $1.86^{* * *}$ & & $1.76^{* *}$ \\
\hline & & $1.35-2.55$ & & $1.24-2.52$ \\
\hline \multirow[t]{2}{*}{ Parent did not read to child in past week } & & 1.34 & & 1.18 \\
\hline & & $0.94-1.92$ & & $0.79-1.77$ \\
\hline \multirow[t]{2}{*}{ Parent a poor reader } & & $2.76^{* *}$ & & $3.08^{* *}$ \\
\hline & & $1.53-4.98$ & & $1.60-5.93$ \\
\hline \multicolumn{5}{|c|}{ Biological risk and developmental health } \\
\hline \multirow[t]{2}{*}{ Mother smoked during pregnancy } & & & $1.51^{* *}$ & 1.21 \\
\hline & & & $1.11-2.05$ & $0.86-1.70$ \\
\hline \multirow[t]{2}{*}{ Child small for gestational age } & & & $2.23^{*}$ & 1.63 \\
\hline & & & $1.22-4.10$ & $0.78-3.41$ \\
\hline \multirow[t]{2}{*}{ Child with neurotic behaviors } & & & 1.41 & 1.31 \\
\hline & & & $0.68-2.92$ & $0.57-3.03$ \\
\hline \multirow[t]{2}{*}{ Child with antisocial behaviors } & & & $1.70^{*}$ & 1.47 \\
\hline & & & $1.02-2.85$ & $0.81-2.66$ \\
\hline \multirow[t]{2}{*}{ Child ever seen a speech-language therapist } & & & $2.45^{* *}$ & $2.66^{* *}$ \\
\hline & & & $1.37-4.38$ & $1.36-5.19$ \\
\hline
\end{tabular}

cohort members whose mothers smoked during pregnancy and for those members exhibiting antisocial behaviors, respectively. For cohort members born small for gestational age or having ever seen a speech-language therapist, the increase was more than twofold. In the final model (Model 4), when all measures were included, gender was found to be associated with SLI; specifically, boys were one third less likely than girls to have language impairment. Having no preschooling and living in overcrowded housing also remained independently associated, with these children being 1.5 to 1.75 times more likely than the TL group to have SLI, respectively. Children who had a parent who was a poor reader or who had ever seen a speech-language therapist were approximately 3 times more likely to be in the SLI than the TL group.

We turn now to N-SLI (see Table 3). When all distal factors were included (Model 1), having a single parent and a mother who left school at the minimum age remained independent risk factors for N-SLI, increasing the odds by more than 3 and 4 times, respectively, compared to those in the TL group. In Model 2 all the proximal factors remained independently associated with N-SLI. Cohort members living in overcrowded housing who had no preschooling and were not read to by a parent had an increased risk (2-3 times) of having N-SLI. For those cohort members with a parent who was a poor reader, this risk increased to more than sixfold. Similarly, all the biological risk and developmental health factors (Model 3) remained independently associated with having N-SLI. In particular, those born small for gestational age and those who had ever seen a speech and language therapist were more than 4 times as likely to be in this group. Cohort members with antisocial or neurotic behaviors were approximately 3 times as likely to have N-SLI compared with the TL children. If a cohort member's mother smoked during pregnancy, the child had nearly a $70 \%$ increase in the risk of having N-SLI. In the final combined model, controlling for all measures, nearly all remained independently associated with N-SLI, with roughly the same odds as in the respective models (Models 1,2 , and 3). Notable exceptions were a reduction in the effect of the age at which the cohort member's mother left education and an increase in the risk for those cohort 
Table 3. Multiple logistic regression predicting N-SLI at 5 years of age.

\begin{tabular}{|c|c|c|c|c|}
\hline Odds Ratio $95 \% \mathrm{Cl}$ & Model 1 & Model 2 & Model 3 & Final Model \\
\hline \multicolumn{5}{|c|}{ Distal factors } \\
\hline \multirow[t]{2}{*}{ Gender (Boy) } & 0.81 & & & $0.65^{*}$ \\
\hline & $0.61-1.09$ & & & $0.44-0.97$ \\
\hline \multirow[t]{2}{*}{ Child mother left school at minimum age } & $4.890^{* * *}$ & & & $1.84^{*}$ \\
\hline & $3.07-7.79$ & & & $1.08-3.15$ \\
\hline \multirow{2}{*}{ Mother single parent } & $3.41^{* * *}$ & & & $2.66^{*}$ \\
\hline & $2.08-5.59$ & & & $1.23-5.76$ \\
\hline \multicolumn{5}{|c|}{ Proximal factors (age 5) } \\
\hline \multirow{2}{*}{ Overcrowding } & & $2.56^{* * *}$ & & $2.66^{* * *}$ \\
\hline & & $1.81-3.62$ & & $1.74-4.06$ \\
\hline \multirow[t]{2}{*}{ Child had some kind of preschool } & & $2.88^{* * *}$ & & $2.53^{* * *}$ \\
\hline & & $2.06-3.62$ & & $1.71-4.06$ \\
\hline \multirow[t]{2}{*}{ Parent did not read to child in past week } & & $2.22^{* * *}$ & & $1.76^{*}$ \\
\hline & & $1.60-3.18$ & & $1.15-2.69$ \\
\hline \multirow[t]{2}{*}{ Parent a poor reader } & & $6.44^{* * *}$ & & $6.04^{* * *}$ \\
\hline & & $4.07-10.17$ & & $3.39-10.75$ \\
\hline \multicolumn{5}{|c|}{ Biological risk and developmental health } \\
\hline \multirow[t]{2}{*}{ Mother smoked during pregnancy } & & & $1.68^{* *}$ & 0.90 \\
\hline & & & $1.19-2.36$ & $0.60-1.34$ \\
\hline \multirow[t]{2}{*}{ Child small for gestational age } & & & $4.66^{* * *}$ & $4.55^{* * *}$ \\
\hline & & & $2.81-7.72$ & $2.44-8.49$ \\
\hline \multirow[t]{2}{*}{ Child with neurotic behaviors } & & & $2.95^{* * *}$ & $4.10^{* * *}$ \\
\hline & & & $1.61-5.43$ & $2.12-7.94$ \\
\hline \multirow[t]{2}{*}{ Child with antisocial behaviors } & & & $3.22^{* * *}$ & $2.55^{* *}$ \\
\hline & & & $2.04-5.11$ & $1.46-4.45$ \\
\hline \multirow[t]{2}{*}{ Child ever seen a speech-language therapist } & & & $4.58^{* * *}$ & $7.17^{* * *}$ \\
\hline & & & $2.78-7.556$ & $4.01-12.83$ \\
\hline
\end{tabular}

members who had ever seen a speech-language therapist. Smoking during pregnancy was no longer significantly associated with N-SLI, and gender was now found to be significant, with boys nearly half as likely to be in the N-SLI group when controlling for the other factors.

\section{Research Question 2: What is the risk associated with early developmental language difficulties in terms of literacy, mental health, and employment at 34 years?}

In the next step, we ran a series of nested multivariate logistic regressions to assess the risk of poor adult literacy, mental health difficulties, and unemployment at 34 years among cohort members with poor language skills at age 5 and whether this risk is moderated by early experiences in the family context. We first assessed the direct effect of early receptive language problems on adult literacy (Model 1). We then added distal sociodemographic indicators such as gender, family characteristics, etc. (Model 2). We added proximal factors experienced at age 5 (Model 3) and then included indicators of early biological risk and developmental health factors (Model 4). In the final model we added all variables simultaneously (Model 5). Typical language skills were again used as a baseline. Results of the multivariate logistic regression models are given in Table 4.

\section{Literacy}

Model 1. Differences in adult literacy were significantly associated with early receptive language problems. The odds for poor adult literacy among children with N-SLI were more than 7 times higher (7.69) than for children with TL and twice as high for children with SLI.

Model 2. Adjusting for sociodemographic characteristics of the family environment reduces the risk for poor literacy in adulthood by $7.5 \%$ and $19 \%$ among individuals with SLI and N-SLI, respectively. However, the odds of poor literacy among those children with N-SLI were still more than 6 times greater than for the TL group (6.25).

Model 3. Adjusting for the proximal factors at age 5 brings a $\mathbf{1 5 . 5 \%}$ reduction of risk for poor adult literacy 
Table 4. Multiple logistic regression predicting poor reading at age 34.

\begin{tabular}{|c|c|c|c|c|c|}
\hline Odds Ratio $95 \% \mathrm{Cl}$ & Model 1 & Model 2 & Model 3 & Model 4 & Final Model \\
\hline \multicolumn{6}{|c|}{ Receptive language (age 5) } \\
\hline \multicolumn{6}{|l|}{ TL } \\
\hline \multirow[t]{2}{*}{ SLI } & $2.00^{* * *}$ & $1.85^{* * *}$ & $1.69^{* * *}$ & $1.89^{* * *}$ & $1.59^{* *}$ \\
\hline & $1.52-2.70$ & $1.39-2.50$ & $1.27-2.27$ & $1.39-2.56$ & $1.16-2.13$ \\
\hline \multirow[t]{2}{*}{ N-SLI } & $7.69^{* * *}$ & $6.25^{* * *}$ & $5.26^{* * *}$ & $6.25^{* * *}$ & $4.35^{* * *}$ \\
\hline & $4.35-12.50$ & $3.70-11.11$ & $3.13-9.09$ & $3.70-11.11$ & $2.50-7.14$ \\
\hline \multicolumn{6}{|c|}{ Distal factors } \\
\hline \multirow[t]{2}{*}{ Gender (Boy) } & & 1.09 & & & 1.05 \\
\hline & & $0.96-1.23$ & & & $0.93-1.20$ \\
\hline \multirow[t]{2}{*}{ Child mother left school at minimum age } & & $1.96^{* * *}$ & & & $1.66^{* * *}$ \\
\hline & & $1.72-2.22$ & & & $1.44-1.91$ \\
\hline \multirow[t]{2}{*}{ Mother single parent } & & $1.47^{*}$ & & & $1.39^{*}$ \\
\hline & & $1.09-1.99$ & & & $1.03-1.88$ \\
\hline \multicolumn{6}{|c|}{ Proximal factors (age 5) } \\
\hline \multirow[t]{2}{*}{ Overcrowding } & & & $1.48^{* * *}$ & & $1.36^{* * *}$ \\
\hline & & & $1.32-1.66$ & & $1.20-1.54$ \\
\hline \multirow[t]{2}{*}{ Child had no preschooling } & & & $1.39^{* * *}$ & & $1.24^{*}$ \\
\hline & & & $1.18-1.63$ & & $1.03-1.48$ \\
\hline \multirow[t]{2}{*}{ Parent did not read to child in past week } & & & $1.32^{* * *}$ & & $1.21^{* *}$ \\
\hline & & & $1.14-1.52$ & & $1.05-1.39$ \\
\hline \multirow[t]{2}{*}{ Parent a poor reader } & & & $1.80^{* * *}$ & & $1.64^{*}$ \\
\hline & & & $1.28-2.52$ & & $1.13-2.38$ \\
\hline \multicolumn{6}{|c|}{ Biological risk and developmental health } \\
\hline \multirow[t]{2}{*}{ Mother smoked during pregnancy } & & & & $1.36^{* * *}$ & $1.15^{*}$ \\
\hline & & & & $1.20-1.53$ & $1.01-1.32$ \\
\hline \multirow[t]{2}{*}{ Child small for gestational age } & & & & 1.34 & 1.35 \\
\hline & & & & $0.96-1.88$ & $0.97-1.87$ \\
\hline \multirow[t]{2}{*}{ Child with neurotic behaviors } & & & & 1.10 & 1.07 \\
\hline & & & & $0.82-1.48$ & $0.79-1.45$ \\
\hline \multirow[t]{2}{*}{ Child with antisocial behaviors } & & & & $1.58^{* * *}$ & $1.40^{* *}$ \\
\hline & & & & $1.30-1.93$ & $1.14-1.71$ \\
\hline \multirow[t]{2}{*}{ Child ever seen a speech-language therapist } & & & & 1.35 & 1.41 \\
\hline & & & & $0.95-1.89$ & $1.00-2.00$ \\
\hline
\end{tabular}

for those with SLI and a $31.6 \%$ reduction for those with N-SLI. Nevertheless, the associated risk of poor adult literacy among children with SLI and N-SLI remains significant for both groups of children (1.69 and 5.26).

Model 4. Adjusting for indicators of biological risk and developmental health also brings a reduction of risk associated with early difficulties. Interestingly, the reduction of risk is again stronger among those with N-SLI than among those with SLI. Among those with N-SLI, the reduction in risk was 19\% (6.25), whereas for those individuals with SLI it was 5.5\% (1.89).

Model 5. The full model was then adjusted for all the above factors. The risk for poor adult literacy among those children with N-SLI in early childhood reduced by around $43.4 \%$ (4.35), remaining significant, as did the risk for the SLI group, reducing by $20.5 \%$ (1.59) when controlling for proximal and biological/developmental variables. In addition, and above the direct influence of N-SLI on poor adult literacy, we find independent significant effects for all of the proximal factors; for the child's mother smoking during pregnancy, leaving education at the minimum age, and being single; and for the cohort member having antisocial behaviors, suggesting that these are key factors undermining potential catch-up in language development. Similarly, having seen a speech-language therapist in the early years continues to be associated with poor adult outcomes, highlighting the role that clinical identification can play in picking out children most at risk.

\section{Mental Health}

Of our sample we had 5,702 cases with data on mental health. Of these, $413(7.2 \%)$ reported three or more 
negative signs, whereas 3,893 had no signs at all. Recall that a further 1,596 had one or two signs only and were excluded from further analysis on the grounds that the difficulties they experienced were insufficiently severe to warrant classifying them as cases.

Model 1. Differences in adult mental health were significantly associated with early receptive language problems (see Table 5). The odds for poor adult mental health among children with N-SLI were more than 5 times higher (5.49) than those among the TL group. For the SLI group the odds were double those of the typically developing children.

Model 2. Adjusting for sociodemographic characteristics of the family environment reduces the risk for poor mental health in adulthood by $11 \%$ in N-SLI individuals. However, the odds of poor mental health among those children with N-SLI were still 5 times greater than those in the TL group (4.90), whereas the odds for the SLI group remained broadly the same.

Model 3. Adjusting for the proximal factors at age 5 brings a $31 \%$ reduction of risk for poor adult mental health for those with N-SLI, although it remains significant (3.77), with a similar pattern for the SLI group, showing a $17 \%$ reduction in odds (1.75).

Model 4. Adjusting for indicators of biological risk and developmental health again brings a $22 \%$ reduction of risk among those with N-SLI and SLI. This reduction in risk was $23 \%$ and $15 \%$ for the N-SLI and the SLI groups, respectively.

Model 5. The full model was then adjusted for all the above factors. Although the risk for poor adult mental

Table 5. Multiple logistic regression predicting mental health difficulties at age 34 .

\begin{tabular}{|c|c|c|c|c|c|}
\hline Odds Ratio $95 \% \mathrm{Cl}$ & Model 1 & Model 2 & Model 3 & Model 4 & Final Model \\
\hline \multicolumn{6}{|c|}{ Receptive language (age 5) } \\
\hline \multicolumn{6}{|l|}{$\mathrm{TL}$} \\
\hline \multirow[t]{2}{*}{ SLI } & $2.11^{* *}$ & $1.99^{* *}$ & $1.75^{*}$ & $1.80^{*}$ & 1.50 \\
\hline & $1.29-3.46$ & $1.21-3.25$ & $1.05-2.91$ & $1.04-3.11$ & $0.85-2.63$ \\
\hline \multirow[t]{2}{*}{ N-SLI } & $5.49^{* * *}$ & $4.90^{* * *}$ & $3.77^{* * *}$ & $4.23^{* * *}$ & $2.90^{* *}$ \\
\hline & $3.17-9.52$ & $2.86-8.40$ & $2.04-6.95$ & $2.26-7.89$ & $1.46-5.79$ \\
\hline \multicolumn{6}{|c|}{ Distal factors } \\
\hline \multirow[t]{2}{*}{ Gender (Boy) } & & 0.98 & & & 0.96 \\
\hline & & $0.74-1.29$ & & & $0.72-1.28$ \\
\hline \multirow[t]{2}{*}{ Child mother left school at minimum age } & & $1.56^{* * *}$ & & & $1.22^{*}$ \\
\hline & & $1.35-1.82$ & & & $1.03-1.45$ \\
\hline \multirow[t]{2}{*}{ Mother single parent } & & 1.45 & & & 1.33 \\
\hline & & $0.78-2.70$ & & & $0.72-2.44$ \\
\hline \multicolumn{6}{|c|}{ Proximal factors (age 5) } \\
\hline \multirow[t]{2}{*}{ Overcrowding } & & & $1.67^{* * *}$ & & $1.64^{* * *}$ \\
\hline & & & $1.39-1.96$ & & $1.35-1.96$ \\
\hline \multirow[t]{2}{*}{ Child had no preschooling } & & & $1.30^{*}$ & & $1.22^{*}$ \\
\hline & & & $1.11-1.52$ & & $1.03-1.43$ \\
\hline \multirow[t]{2}{*}{ Parent did not read to child in past week } & & & 1.09 & & 1.03 \\
\hline & & & $0.84-1.41$ & & $0.79-1.33$ \\
\hline \multirow[t]{2}{*}{ Parent a poor reader } & & & $2.13^{* *}$ & & $1.92^{*}$ \\
\hline & & & $1.32-3.45$ & & $1.18-3.13$ \\
\hline \multicolumn{6}{|c|}{ Biological risk and developmental health } \\
\hline \multirow[t]{2}{*}{ Mother smoked during pregnancy } & & & & $1.45^{* * *}$ & $1.27^{* *}$ \\
\hline & & & & $1.25-1.69$ & $1.08-1.49$ \\
\hline \multirow[t]{2}{*}{ Child small for gestational age } & & & & 1.43 & 1.43 \\
\hline & & & & $0.85-2.38$ & $0.87-2.38$ \\
\hline \multirow[t]{2}{*}{ Child with neurotic behaviors } & & & & $2.13^{*}$ & $2.13^{*}$ \\
\hline & & & & $1.15-4.00$ & $1.14-4.00$ \\
\hline \multirow[t]{2}{*}{ Child with antisocial behaviors } & & & & $2.22^{* * *}$ & $2.08^{* *}$ \\
\hline & & & & $1.47-3.45$ & $1.33-3.23$ \\
\hline \multirow[t]{2}{*}{ Child ever seen a speech-language therapist } & & & & 1.20 & 1.28 \\
\hline & & & & $0.73-1.96$ & $0.77-2.12$ \\
\hline
\end{tabular}


health among those children with N-SLI in early childhood was reduced by around 47\% (2.9), it remained significant when controlling for all the distal, proximal, and biological/developmental factors. In addition, and above the direct influence of N-SLI on poor adult mental health, we find an independent significant effect from the cohort member's mother leaving education at the minimum age; for the child living in overcrowded housing; and for the child having had preschooling, behavioral difficulties, a parent who was a poor reader, and a mother who smoked during pregnancy.

\section{Unemployment}

Model 1. Differences in time spent unemployed (12 months or fewer, more than 12 months) were significantly associated with early receptive language problems (see Table 6). The odds for higher parental unemployment among children with N-SLI were nearly 3 times higher (2.88) than for the TL group and more than 2.5 times as high for the SLI group (2.61).

Model 2. Adjusting for the sociodemographic characteristics of the family environment barely changed the risk, and hence the odds, for greater time spent by parents in unemployment among SLI and N-SLI individuals.

Model 3. Adjusting for the proximal factors at age 5 brings a $27 \%$ reduction for those in the N-SLI group and $14 \%$ for those in the SLI group. The associated risk of parental unemployment among children with a history of N-SLI or SLI remained significant (2.11 and 2.25, respectively).

Model 4. Adjusting for indicators of biological risk and developmental health brings a reduction of risk among

Table 6. Multiple logistic regression predicting unemployment up to 34 years of age.

\begin{tabular}{|c|c|c|c|c|c|}
\hline Odds Ratio $95 \% \mathrm{Cl}$ & Model 1 & Model 2 & Model 3 & Model 4 & Final Model \\
\hline \multicolumn{6}{|c|}{ Receptive language (age 5) } \\
\hline \multicolumn{6}{|l|}{ TL } \\
\hline \multirow[t]{2}{*}{ SLI } & $2.61^{* * *}$ & $2.76^{* * *}$ & $2.25^{* * *}$ & $2.34^{* * *}$ & $2.24^{* * *}$ \\
\hline & $1.78-3.83$ & $1.83-4.14$ & $1.51-3.36$ & $1.57-3.47$ & $1.45-3.48$ \\
\hline \multirow[t]{2}{*}{ N-SLI } & $2.88^{* * *}$ & $2.82^{* * *}$ & $2.11^{* *}$ & $2.39^{* *}$ & $1.88^{*}$ \\
\hline & $1.84-4.51$ & $1.78-4.46$ & $1.34-3.34$ & $1.41-4.04$ & $1.04-3.39$ \\
\hline \multicolumn{6}{|c|}{ Distal factors } \\
\hline \multirow[t]{2}{*}{ Gender (boy) } & & $2.15^{* *}$ & & & $2.05^{* * *}$ \\
\hline & & $1.68-2.74$ & & & $1.61-2.62$ \\
\hline \multirow[t]{2}{*}{ Child mother left school at minimum age } & & 1.16 & & & 0.97 \\
\hline & & $0.88-1.54$ & & & $0.73-1.28$ \\
\hline \multirow[t]{2}{*}{ Mother single parent } & & $1.96^{* *}$ & & & $1.92^{* *}$ \\
\hline & & $1.28-3.03$ & & & $1.28-2.86$ \\
\hline \multicolumn{6}{|c|}{ Proximal factors (age 5) } \\
\hline \multirow[t]{2}{*}{ Overcrowding } & & & $1.56^{* * *}$ & & $1.59^{* * *}$ \\
\hline & & & $1.32-1.89$ & & $1.28-1.96$ \\
\hline \multirow[t]{2}{*}{ Child had no preschooling } & & & $1.35^{*}$ & & $1.33^{*}$ \\
\hline & & & $1.04-1.79$ & & $1.03-1.72$ \\
\hline \multirow[t]{2}{*}{ Parent not read to child in past week } & & & 0.94 & & 0.94 \\
\hline & & & $0.71-1.25$ & & $0.68-1.28$ \\
\hline \multirow[t]{2}{*}{ Parent a poor reader } & & & 1.61 & & 1.54 \\
\hline & & & $1.00-2.56$ & & $0.91-2.63$ \\
\hline \multicolumn{6}{|c|}{ Biological risk and developmental health } \\
\hline \multirow[t]{2}{*}{ Mother smoked during pregnancy } & & & & $1.27^{*}$ & 1.14 \\
\hline & & & & $1.03-1.56$ & $0.93-1.39$ \\
\hline \multirow[t]{2}{*}{ Child small for gestational age } & & & & 1.26 & 1.18 \\
\hline & & & & $0.68-2.31$ & $0.64-2.21$ \\
\hline \multirow[t]{2}{*}{ Neurotic behaviors } & & & & 1.14 & 1.16 \\
\hline & & & & $0.62-2.08$ & $0.62-2.17$ \\
\hline \multirow[t]{2}{*}{ Child with antisocial behaviors } & & & & $1.67^{* *}$ & $1.45^{*}$ \\
\hline & & & & $1.20-2.33$ & $1.05-2.00$ \\
\hline \multirow[t]{2}{*}{ Child ever seen a speech-language therapist } & & & & 1.51 & 1.46 \\
\hline & & & & $0.91-2.50$ & $0.86-2.46$ \\
\hline
\end{tabular}


those children, with both the N-SLI and SLI groups associated with longer unemployment when controlling for the biological risk and developmental health factors. Among those with N-SLI the reduction in risk was 17\% (2.39); in the SLI group it was $11 \%$ (2.33).

Model 5. The full model was adjusted for all the above factors. Although the risk was reduced for the $\mathrm{N}-\mathrm{SLI}$ group by around 35\% (1.88), it still remained significantly associated, as did that for the SLI group, with a $14 \%$ reduction (2.24) when controlling for distal, proximal, and biological/developmental factors. In addition, and above the direct influence of N-SLI and SLI status on time spent in unemployment, we find independent significant effects for gender (boys being more likely), mother being a single parent, overcrowded housing, child having no preschooling, and the child presenting with antisocial behaviors.

\section{$\overline{\text { Discussion }}$}

The results of these analyses show that the pattern of demographic and within-child variables at school entry are closely associated with both SLI and N-SLI groups, although the pattern and the strength of individual associations in the multivariate analyses vary considerably. The overall profile is in line with the findings of Dollaghan et al. (1999), Hart and Risley (1995), Locke et al. (2002), and others but has the added advantage of being generated from a whole population and covering such a wide time period. Indeed, this, together with the measure of receptive language adopted in the present study, probably explains the rather different findings from studies looking at shorter follow-up with younger children (Reilly et al., 2007; Zubrick et al., 2007). It is quite possible that this difference may also be partially explained by the stronger association of demographic factors with receptive language than with expressive language (Clark et al., 2007; Kovas et al., 2005). The difference between the findings for the SLI and N-SLI groups is instructive because, at school entry, demographic factors are closely associated with both SLI and N-SLI groups, but this relationship is especially pronounced for the N-SLI group. The results of the 34-year follow-up again suggest that, although the SLI group is associated with poor reading, mental health, and employment, there is a sense in which the "specific" nature of these children's difficulties may protect them from the kind of long-term impact that is such a clear feature of the N-SLI group, at least as far as mental health is concerned. Interestingly, the pattern of increased risk for the N-SLI group disappears when it comes to unemployment. The data suggest that there is little difference between the two groups, the SLI group having a marginally greater chance of long-term parental unemployment. Of course, these outcomes are not unrelated. Those with poor literacy skills are more likely to have poor mental health and difficulty holding down a job. But it is of note that the less obvious problems exhibited by the SLI group may make them rather less likely to have long-term mental health difficulties once demographic factors are taken into consideration and correspondingly more likely to experience sustained parental unemployment.

It is also important to acknowledge that, although many of the associations between independent factors in the logistic regression models are statistically significant, it does not mean that the resultant model explains much of the variance in the dependent variable, only that however much or little it does explain is statistically significant. The different models were relatively poor at categorizing the children across time, this being fairly typical of those seen in logistic regression applications. Indeed, as two other analyses from this project have indicated, at an individual level, many of the young people with early difficulties have positive literacy outcomes, whether at the end of primary school (Parsons, Schoon, Rush, \& Law, in press) or in adulthood (Schoon, Parsons, Rush, \& Law, in press). As noted by Hosmer and Lemeshow (2004), "Classification is sensitive to the relative sizes of the two component groups and always favors classification into the larger group, a fact that is also independent of the fit of the model" (p. 157).

In this study, the assessment used to identify developmental language difficulties was the EPVT, and there remains a question as to whether this test identifies the types of difficulties commonly identified by clinical services. On the one hand, the measure has strong clinical face validity and continues to be used by speech-language clinicians and psychologists, and children with language impairment are commonly characterized as having poor vocabulary. On the other hand, concerns have been raised as to whether all children with developmental language difficulties necessarily have difficulties with vocabulary. For example, Gray and colleagues found that children with confirmed SLI did not necessarily have vocabulary difficulties as measured on a variety of vocabulary scales, one of which was the Peabody Picture Vocabulary Test, the U.S. version of the EPVT (Gray, Plante, Vance, \& Henrichsen, 1999). We would maintain that vocabulary difficulties of the type described here are a sufficient but not a necessary condition for language learning difficulties. It is difficult to conceive of a situation where the level of difficulties described in the present study would not lead to a substantive developmental language difficulty, but the reverse is not necessarily the case. Those with primarily expressive difficulties would not necessarily present with poor vocabulary skills.

One feature of the present analysis has been the relatively poor performance of girls. Studies of clinical 
samples have continually indicated that boys do worse than girls, but this is not reflected in the present results. In part, this is probably a function of the way in which these data are collected. The pattern in clinical samples has not generally been repeated in large population samples. In fact, the odds ratios are commonly close to or include parity (i.e., 1.0), and this rather points to a gender equilibrium (Law, Rush, Schoon, \& Parsons, 2009). The proportions in this study are, in fact, comparable (94.9\% of the girls were in the TL groups, and $96.1 \%$ of the boys). Interestingly, if we then look at the proportion of children having seen a speech-language therapist, the relationship reverses, with $4.7 \%$ of the boys and $2.4 \%$ of the girls having done so, suggesting that boys may receive a disproportionate proportion of the available resources relative to their actual need, at least in terms of the measures reported in this study.

Another feature of the analysis is the association between having seen a speech-language therapist and the different study outcomes. This may appear anomalous, given the potentially positive results of intervention (Law, Garrett, \& Nye 2004), but it does probably reflect the fact that the children identified in this study had serious developmental language difficulties (below the second percentile), and this is almost certainly demonstrated in their referral to speech-language therapy services. But the fact that the SLI group would appear to have more positive outcomes suggests that they may be more amenable to positive environmental influences across childhood, which, at least in the 1970s and 1980s when these data were collected, were not necessarily associated with speech-language therapy.

The fact that these data are derived from two timepoints with nearly 30 years between them may oversimplify the relationship between environment and outcome. It is clear that the timing and duration of exposure to risk is likely to make a difference in the outcomes of the children (Schoon et al., 2002). This may be particularly true of the proximal variables, which directly affect the child's experience. For example, variables measuring level of overcrowding or parental reading have an immediate effect on the child when this is reported at 5 years, but circumstances change, and it does not follow that the child will experience negative environmental influences throughout their life. The other side to this, of course, is that there may be reciprocal effects derived directly from the child's lack of facility with language that may result in chained effects through childhood and into adulthood.

As indicated above, there has been considerable discussion of the value of discrepancy criteria related to SLI, as there has been with other specific learning difficulties. In general, the literature suggests that these children defy classification across time, moving from one category to another without any obvious developmental reason. A recent secondary analysis of the Conti-Ramsden Manchester Child Language Cohort has suggested that, at least as far as receptive language is concerned, it is the severity of the impairment at the time of diagnosis that is critical in determining outcome rather than any specific diagnostic category or combination of symptoms (Law, Tomblin, \& Zhang, 2008). But recall that the children in this study had been identified through clinical means and were not part of a population sample. The 34-year data for reading and mental health in the present study suggest that there may indeed be something significant in the discrepancy over time, such that the long-term outcomes of the SLI group would appear to be better than for the N-SLI group, the relatively advanced nonverbal performance effectively protecting those concerned. Of course, this is a group effect, and given that many of these children may have received no support services within schools, it is quite possible that there are some children in this group who have very marked persistent difficulties.

The two notional "clinical" groups identified in the present study are, of course, not clinical groups as such but are generated from the normal population using a comparatively limited range of measures. Thus, SLI groups would traditionally be identified by a pattern of responses on measures of expressive language, morphology, grammatical relations, etc., rather than their comprehension alone. Receptive language is commonly left to vary, the assumption being that many children with expressive SLI would also have receptive language difficulties and that these would probably reflect the severity of the condition. In adopting what Stark and Tallal (1981) would call a "properly conservative" model of SLI, we may have identified a more stringently defined group than would be the custom in clinical practice. This is reflected in the prevalence data, which suggest that the SLI and the N-SLI groups combined constituted approximately $4 \%$ of the population, only half of the $7.4 \%$ obtained by Tomblin and colleagues using more liberal criteria (Tomblin et al., 1997). Nevertheless, the cutpoint is likely to be closely associated with major delays in the child's expressive language skills (Bishop, 2006). It is, of course, possible that these children would not necessarily have presented in the same way on other tests. This may well be true for measures of speech or expressive language but is unlikely to be so for other measures of comprehension. Under the present circumstances, children with isolated speech or expressive language difficulties would be placed in the TL group and would effectively lower any associations identified in the two target groups. Nonetheless, we would maintain that the EPVT represents a very conservative measure with which to identify language learning difficulties, and those with 
low scores on this measure are very unlikely to have much higher scores on other language measures.

Finally, it is important to turn to the clinical and research implications of these findings. The application of epidemiological interpretations of data in speechlanguage pathology is still relatively uncommon. In the main, researchers in the field adopt experimental paradigms, identifying extreme groups of cases and then matching them to language-typical comparisons. One of the messages from the present data, reflecting those of other studies in the field, concerns the very high level of comorbidity associated with language impairment and the necessary effect that this will have on comparison groups in empirical studies. For example, it is common for researchers to control for language level but do little to control for developmental or demographic risk. Given the significant level of associations between such factors and developmental language difficulties, differences between two study populations are as likely to be a function of the comorbidities as they are to be a function of the language level, a factor rarely acknowledged by those concerned. Our findings would support the "continuum of reproductive casualty" - which suggests that the poorest scores are strongly associated with the highest level of risks in a range of other areas - and suggest that the continuum applies to developmental language difficulties (Lubker \& Tomblin, 1998). The difference between the $\mathrm{N}-\mathrm{SLI}$ and the SLI groups in the present study may well be simply a reflection of their respective positions on this continuum. In this model, N-SLI would simply represent the more severe end of the continuum, akin to mental retardation, with SLI at the milder end of the continuum, like other specific learning difficulties. At the more severe end, there are clear links with antenatal and within-child factors; at the milder end, these associations become less pronounced.

\section{$\overline{\text { Conclusions }}$}

This study is one of a small number of investigations that have aimed to identify a group of children with poor language learning skills based on test performance alone. This approach makes it possible to demonstrate the factors associated with language learning difficulties in the population as a whole rather than following the usual pattern of restricting the analysis to groups of children with clinically identified problems. The results suggest that early language learning difficulties are clearly linked to literacy, mental health, and employment outcomes in adulthood and that this holds over and above common demographic markers. There is considerable potential in employing this approach in exploring the long-term impacts of different early linguistic/demographic profiles.

\section{Acknowledgment}

We acknowledge the support of the Economic and Social Science Research Council (RES-000-22-1748) in the preparation of this article.

\section{References}

Bishop, D. V. M. (2006). Developmental cognitive genetics: How psychology can inform genetics and vice-versa. Quarterly Journal of Experimental Psychology, 59, 1153-1168.

Brimer, M. A., \& Dunn, L. M. (1962). English Picture Vocabulary Test. Bristol, United Kingdom: Evaluation Enterprises.

Bynner, J., Joshi, H., \& Tsatsas, M. (2000). Obstacles and opportunities on the route to adulthood. London: The Smith Institute.

Clark, A., O'Hare, A., Watson, J., Cohen, W., Cowie, H., Elton, R., et al. (2007). Receptive language disorder in childhood: Familial aspects and long-term outcomes: Results from a Scottish Study. Archives of Disease in Childhood, 92, 614-619.

Clegg, J., Hollis, C., Mawhood, L., \& Rutter, M. (2005). Developmental language disorders - a follow-up in later adult life. Cognitive, language and psychosocial outcomes. Journal of Child Psychology and Psychiatry and Allied Disciplines, $46,128-149$.

Cole, K. N., Dale, P. S., \& Mills, P. E. (1992). Stability of the intelligence quotient relation: Is discrepancy modeling based on a myth? American Journal on Mental Retardation, 97, 131-145.

Conti-Ramsden, G., \& Botting, N. (1999). Classification of children with specific language impairment: Longitudinal considerations. Journal of Speech, Language, and Hearing Research, 42, 1195-1204.

Dex, S., \& Joshi, H. (2004). Millennium Cohort Study first survey: A user's guide to initial findings. London: Centre for Longitudinal Studies.

Dollaghan, C. A., Campbell, T. F., Paradise, J. L., Feldman, H. M., Janosky, J. E., Pitcairn, D. N., \& Kurs-Lasky, M. (1999). Maternal education and measures of early speech and language. Journal of Speech, Language, and Hearing Research, 42, 1432-1443.

Dunn, L. M. (1965). Expanded manual: Peabody Picture Vocabulary Test. Minneapolis, MN: AGS.

Fazio, B., Naremore, R. C., \& Connell, P. J. (1996). Tracking children from poverty at risk from specific language impairment: A 3-year longitudinal study. Journal of Speech and Hearing Research, 39, 611-624.

Felsenfeld, S., Broen, P. A., \& McGue, M. (1992). A twentyeight year follow-up of adults with a history of moderate phonological disorder: Linguistic and personality results. Journal of Speech and Hearing Research, 35, 1114-1125.

Felsenfeld, S., Broen, P. A., \& McGue, M. (1994). A twentyeight year follow-up of adults with a history of moderate phonological disorder: Educational and occupational results. Journal of Speech and Hearing Research, 37, 1341-1353.

Gray, S., Plante, E., Vance, R., \& Henrichsen, M. (1999). The diagnostic accuracy of four vocabulary tests administered to 
pre-school children. Language, Speech and Hearing Services in Schools, 30, 196-206.

Hart, B., \& Risley, T. (1995). Meaningful differences in the everyday experiences of young American children. Baltimore: Paul Brookes.

Hayiou-Thomas, M. E., Oliver, B., \& Plomin, R. (2005). Genetic influences on specific versus non-specific language impairment in 4-year-old twins. Journal of Learning Disabilities, 38, 222-232.

Hosmer, D. W., \& Lemeshow, S. (2004). Applied logistic regression: Textbook and solutions manual. London: Wiley-IEEE.

Howlin, P., Mawhood, L., \& Rutter, M. (2000). Autism and developmental receptive language disorder-A follow-up comparison in early adult life. II: Social, behavioural, and psychiatric outcomes. Journal of Child Psychology and Psychiatry, 41, 561-578.

Im-Bolterm, N., \& Cohen, N. J. (2007). Language impairment and psychiatric comorbidities language, communication, and literacy: Pathologies and treatments. Pediatric Clinics of North America, 54, 525-542.

Johnson, C. J., Beitchman, J. H., Young, A., Escobar, M., Atkinson, L., Wilson, B., et al. (1999). Fourteen-year follow-up of children with and without speech/language impairments: Speech/language stability and outcomes. Journal of Speech, Language, and Hearing Research, 42, 744-761.

Kovas, Y., Hayiou-Thomas, M. E., Oliver, B., Dale, P. S., Bishop, D. V., \& Plomin, R. (2005). Genetic influences in different aspects of language development: The etiology of language skills in 4.5-year-old twins. Child Development, $76,632-651$.

Law, J., Garrett, Z., \& Nye, C. (2004). The effectiveness of speech and language therapy interventions for children with primary speech and language delay or disorder. Journal of Speech, Language, and Hearing Research, 47, 924-943.

Law, J., Tomblin, B., \& Zhang, X. (2008). Characterizing the growth trajectories of language impaired children between 7 and 11 years of age. Journal of Speech, Language, and Hearing Research, 51, 739-750.

Law, J., Rush, R., Schoon, I., \& Parsons, S. (2009). The relationship between gender, receptive language and literacy from school entry through to adulthood: Findings from the BCS70 birth cohort. Manuscript submitted for publication.

Locke, A., Ginsborg, J., \& Peers, I. (2002). Development and disadvantage: Implications for the early years and beyond. International Journal of Language and Communication Disorders, 37, 3-15.

Lubker, B. B., \& Tomblin, J. B. (1998). Epidemiology: Informing clinical practice and research on language disorders in children. Topics in Language Disorders, 19, 1-26.

Monaco, A. P., \& The SLI Consortium. (2007). Multivariate linkage analysis of specific language impairment (SLI). Annals of Human Genetics, 71, 1-14.

Nelson, R. J., Benner, G. J., Stern, N., \& Stage, S. A. (2006). Interrelationships among language skills, externalizing behavior, and academic fluency and their impact on the academic skills on students with ED. Journal of Emotional and Behavioral Disorders, 14, 209-216.
Osborn, A. F., Butler, N. R., \& Morris, A. C. (1984). The social life of Britain's five-year-olds. London: Routledge and Kegan Paul.

Parsons, S., Schoon, I., Rush, R., \& Law, J. (in press). Longterm outcomes for children with early language problems: Beating the odds. Children and Society.

Plante, E. (1998). Criteria for SLI: The Stark and Tallal legacy and beyond. Journal of Speech, Language, and Hearing Research, 41, 951-957.

Richman, N., Stevenson, J., \& Graham, P. J. (1982). Preschool to school: A behavioural study. London: Academic Press.

Reilly, S., Wake, M., Bavin, E. L., Prior, M., Williams, J., Bretherton, L., et al. (2007). Predicting language at 2 years of age: A prospective community study. Pediatrics, 120, 1441-1449.

Rose, D. (1995, July). Official social classifications in the UK. Social Research Update, 9. Available at http://sru.soc.surrey. ac.uk/index.html.

Royston, P. (2004). Multiple imputation of missing values. The Stata Journal, 4, 227-241.

Rubin, D. B. (1987). Multiple imputation for non-response in surveys. New York: John Wiley \& Sons.

Rutter, M., Tizard, J., \& Whitmore, K. (1970). Education, health and behaviour. London: Longman.

Schoon, I. (2006). Risk and resilience: Adaptations in changing times. Cambridge, United Kingdom: Cambridge University Press.

Schoon, I., Brynner, J., Joshi, H., Parsons, S., Wiggins, R. D., \& Sacker, A. (2002). The influence of context, timing, and duration of risk experiences for the passage from childhood to mid-adulthood. Child Development, 73, 1486-1504.

Schoon, I., Parsons, S., Rush, R., \& Law, J. (in press). Childhood language skills and adult literacy: A twenty-nine year follow-up study. Pediatrics.

Silva, P. A., Williams, S., \& McGee, R. (1987). A longitudinal study of children with developmental language delay at age three: Later intelligence, reading and behaviour problems. Developmental Medicine and Child Neurology, 29, 630-640.

Snowling, M. J., Bishop, D. V. M., Stothard, S. E., \& Kaplan, C. (2006). Psychosocial outcomes at 15 years of children with a preschool history of speech-language impairment. Journal of Child Psychology and Psychiatry, 47, 759-765.

Stark, R. E., \& Tallal, P. (1981). Selection of children with specific language deficits. Journal of Speech and Hearing Disorders, 46, 114-122.

Stothard, S. E., Snowling, M. J., Bishop, D. V. M., Chipchase, B. B., \& Kaplan, C. A. (1998). Language impaired preschoolers: A follow-up into adolescence. Journal of Speech, Language, and Hearing Disorders, 41, 407-418.

Thomas, M., \& Karmiloff-Smith, A. (2002). Are developmental disorders like cases of adult brain damage?: Implications for connectionist modelling. Behavioral and Brain Science, 25, 727-750.

Tomblin, J. B. (2005). Literacy as an outcome of language development and its impact on children's psychosocial and emotional development. In R. E. Tremblay, R. J. Barr, \& 
R. De. V. Peters (Eds.), Encyclopedia on early childhood development [Online]. Retrieved November 21, 2007, from http://www.enfant-encyclopedie.com/Pages/PDF/ TomblinANGxp.pdf.

Tomblin, J. B., Hammer, C. S., \& Zhang, X. (1998). The association of parental tobacco use and SLI. International Journal of Language and Communication Disorders, 33, 357-68.

Tomblin, J. B., Records, N. L., Buckwalter, P., Zhang, X., Smith, E., \& O'Brien, M. (1997). Prevalence of specific language impairment in kindergarten. Journal of Speech, Language, and Hearing Research, 40, 1245-1269.

World Health Organization. (1993). International Statistical Classification of Diseases and Related Health Problems [ICD-10]. Geneva, Switzerland: Author.

Zaichik, L. I., Tomblin, R. B., Smith, E., \& Xuyang, X. (1997). The epidemiology of specific language impairment: Prenatal and perinatal risk factors. Journal of Communication Disorders, 30, 325-344.
Zubrick, S. R., Taylor, C. L., Rice, M. L., \& Slegers, D. W. (2007). Late language emergence at 24 months: An epidemiological study of prevalence, predictors, and covariates. Journal of Speech, Language, and Hearing Research, 50, 1562-1592.

Received August 5, 2008

Accepted March 21, 2009

DOI: $10.1044 / 1092-4388(2009 / 08-0142)$

Contact author: James Law, Queen Margaret University, Edinburgh EH21 6UU, United Kingdom.

E-mail: jlaw@qmu.ac.uk. 